\title{
Breast cancer risk and protracted low-to-moderate dose occupational radiation exposure in the US Radiologic Technologists Cohort, 1983-2008
}

\author{
D L Preston *, , C M Kitahara ${ }^{2}$, D M Freedman ${ }^{2}$, A J Sigurdson ${ }^{2}$, S L Simon², M P Little ${ }^{2}$, E K Cahoon ${ }^{2}$, \\ P Rajaraman², J S Miller ${ }^{3}$, B H Alexander ${ }^{4}$, M M Doody ${ }^{2}$ and M S Linet ${ }^{2}$ \\ ${ }^{1}$ Hirosoft International, 1335 H, Eureka, CA 95501, USA; ${ }^{2}$ Radiation Epidemiology Branch, Division of Cancer Epidemiology and \\ Genetics, National Cancer Institute, 9609 Medical Center Drive, Rockville, MD 20850, USA; ${ }^{3}$ Information Management Services \\ Inc., 6110 Executive Boulevard No. 310, Rockville, MD 20852, USA and ${ }^{4}$ Division of Environmental Health Sciences, School of \\ Public Health, University of Minnesota, 426 Church Street SE, Minneapolis, MN 55455, USA
}

Background: Although high-dose ionising radiation is associated with increased breast cancer risks, the association with protracted low-dose-rate exposures remains unclear. The US Radiologic Technologist study provides an opportunity to examine the association between low-to-moderate dose radiation and breast cancer incidence and mortality.

Methods: One thousand nine hundred and twenty-two self-reported first primary cancers were diagnosed during $1983-2005$ among 66915 female technologists, and 586 breast cancer deaths occurred during 1983-2008 among 83538 female cohort members. Occupational breast dose estimates were based on work histories, historical data, and, after the mid-1970s, individual film badge measurements. Excess relative risks were estimated using Poisson regression with birth cohort stratification and adjustment for menopause, reproductive history, and other risk factors.

Results: Higher doses were associated with increased breast cancer incidence, with an excess relative risk at $100 \mathrm{mGy}$ of 0.07 ( $95 \%$ confidence interval $(\mathrm{Cl})$ : -0.005 to 0.19 ). Associations were strongest for technologists born before 1930 (excess relative risk at $100 \mathrm{mGy}=0.16$; 95\% Cl: 0.03-0.39) with similar patterns for mortality among technologists born before 1930.

Conclusions: Occupational radiation to the breast was positively associated with breast cancer risk. The risk was more pronounced for women born before 1930 who began working before 1950 when mean annual doses (37 mGy) were considerably higher than in later years $(1.3 \mathrm{mGy})$. However, because of the uncertainties and possible systematic errors in the occupational dose estimates before 1960, these findings should be treated with caution.

The risk of breast cancer has been associated with moderate and high ionising radiation doses in atomic bomb survivors and radiotherapy patients (United Nations Scientific Committee on the Effects of Atomic Radiation, 2008). However, data on breast cancer risk among women exposed to protracted low-dose radiation exposure are limited. Exposure-response trends for breast cancer have been reported for women who underwent multiple diagnostic $\mathrm{x}$-rays during childhood and adolescence to assess spinal curvature from scoliosis (Ronckers et al, 2008) and for tuberculosis patients with repeated fluoroscopic examinations (Howe and McLaughlin, 1996; Little and Boice, 1999). A cohort study of Russians (Eidemuller et al, 2008; Ostroumova et al, 2008; Davis et al, 2015) with

*Correspondence: Dr DL Preston; E-mail preston@hirosoft.net

Received 27 May 2016; revised 29 July 2016; accepted 9 August 2016; published online 13 September 2016

(c) 2016 Cancer Research UK. All rights reserved 0007 - 0920/16 
low-dose-rate environmental exposures found indications of a dose-response association. Most nuclear worker studies are comprised solely of men; however, a study in the United Kingdom that included women found no evidence of an association between radiation dose and breast cancer rates (Muirhead et al, 2009). Most other occupational studies, including those of medical radiation workers (Linet et al, 2010) and flight crews (Zeeb et al, 2003), were based on work history factors rather than dose estimates.

Using self-reported work history data in the US Radiologic Technologists (USRT) study, we previously reported that technologists who worked before 1950 experienced elevated breast cancer incidence (Doody et al, 2006) and mortality (Mohan et al, 2002) compared with those who first worked after 1959. Hormonal, reproductive, lifestyle, anthropometric, and other known risk factors account for $\sim 40 \%$ of breast cancer cases (Madigan et al, 1995; Sprague et al, 2008), and our earlier analyses of breast cancer incidence in the USRT Cohort (Mohan et al, 2002; Doody et al, 2006) and the WeCare study of second breast cancers (Langholz et al, 2009; Bernstein et al, 2013) are the only studies that examined individual radiation exposure and breast cancer risks adjusting for a broad range of known lifestyle and reproductive risk factors.

The current paper, based on data from the USRT study, describes the first comprehensive dose-response analysis for breast cancer risk among medical radiation workers using individualised annual dose estimates that were based on badge dose measurements available in more recent years covering $\sim 30 \%$ of individual worker total doses, on average, together with information on work history and practices. For each worker, we calculated mean annual breast doses from 1000 dose realisations that reflect the uncertainty in individual annual doses from various sources (Simon et al, 2014). Dose estimates have been corroborated by an analysis of chromosome translocation frequencies in a subset of USRT cohort members that found a radiation dose-response similar to that reported in other radiation-exposed populations (Little et al, 2014). Using risk factor information obtained from three detailed questionnaires administered at roughly 10 -year intervals, we investigated and adjusted for confounding by a wide range of known or suspected breast cancer risk factors.

\section{MATERIALS AND METHODS}

Target population and data sources. Details of the study population and methods are given in Boice et al (1992) and Doody et al (2006) and can be found online at http:// www.radtechstudy.nci.nih.gov (Radiation Epidemiology Branch, 2015). Briefly, in the mid-1980s, the US National Cancer Institute, in collaboration with the University of Minnesota and the American Registry of Radiologic Technologists (ARRT), began a cohort study of 146022 radiologic technologists, including 106953 women, who were certified for at least 2 years between 1926 and 1982 (Sigurdson et al, 2003). Vital status was ascertained from ARRT recertification records and linkage with the Social Security Administration. Cause of death was ascertained from the National Death Index through 31 December 2008.

Work history, behaviour, and cancer incidence data were obtained from three surveys: the first administered between 1983 and 1989 to 98233 female technologists (71\% response); the second administered to 94508 women between 1994 and 1998 (74\% response); and the third administered between 2003 and 2005 to 78506 women (74\% response) who completed at least one previous questionnaire.

Study population and follow-up. The target population for both incidence and mortality follow-up included 83358 female technologists who responded to at least one questionnaire. Incidence analyses were limited to 66915 out of the 83358 technologists who completed at least two questionnaires and reported no cancer other than non-melanoma skin cancer before completing their first questionnaire (2366 women were excluded). Follow-up extended from the first (baseline) questionnaire answered until the earliest of a self-reported diagnosis of a cancer other than non-melanoma skin cancer or the last questionnaire answered. Mortality analyses were based on all 83538 women who completed at least one questionnaire with follow-up from that response date until the date of death or 31 December 2008.

Breast cancer outcomes and medical validation. Incident cases were self-reported first primary malignancies occurring between the first and last questionnaires answered. Medical records were sought for all cases and obtained for 1611 of 1934 (83\%), of which all but 12 (99\%) were confirmed. We excluded the latter. Because medical records were obtained for a high percentage of selfreported cases, nearly all of which were confirmed, the 323 selfreported breast cancers for which medical records could not be obtained were treated as cases. Thus, the study included 1922 incident cases. Mortality analyses were based on 586 breast cancer deaths, $80 \%$ of which had been reported as an incident cases on at least one questionnaire.

Dose estimation. Dose reconstruction was undertaken to estimate individual annual occupational absorbed doses to specific organs (Simon et al, 2014). Input data included: 684465 annual badge dose measurements for 83719 female cohort members between 1960 and 1997 from the nation's largest commercial dosimetry provider, military radiation dose registries, civilian employers, and a major US hospital; detailed information on work procedures and protection practices obtained from the cohort surveys; and literature-derived historical data on badge doses, $\mathrm{x}$-ray imaging technology, radiation protection standards, protection practices, radiation energies and filtration; and other factors affecting exposure (Simon et al, 2014, 2006). The system provides 1000 realisations of breast dose for each cohort member in each year worked. The individual annual dose estimates used for these analyses were the arithmetic means of the 1000 realisations. Tables 1 and 2 present summary information on the doses. Further details on the dosimetry system are given in (Simon et al, 2014) and Supplementary Data A.

Statistical methods. Our a priori approach for the dose-response analyses was to focus on breast cancer incidence using internal comparisons of excess relative risk (ERR) stratified by birth cohort

\begin{tabular}{|c|c|c|c|c|c|}
\hline $\begin{array}{l}\text { Period } \\
\text { worked }\end{array}$ & $\begin{array}{c}\text { Total } \\
\text { years } \\
\text { worked }\end{array}$ & $\begin{array}{l}\text { Mean } \\
\text { years } \\
\text { worked } \\
\text { in } \\
\text { period }\end{array}$ & $\begin{array}{l}\text { Mean } \\
\text { annual } \\
\text { breast } \\
\text { dose } \\
\text { (mGy) }\end{array}$ & $\begin{array}{c}\text { Badge } \\
\text { dose } \\
\text { available } \\
\left(^{(\%)^{a}}\right.\end{array}$ & $\begin{array}{c}\text { Mean } \\
\text { birth } \\
\text { year }\end{array}$ \\
\hline Pre-1930 & 390 & 3 & 84.6 & 0 & 1905 \\
\hline 1930-1939 & 4016 & 4.3 & 82.2 & 0 & 1912 \\
\hline 1940-1949 & 18469 & 4.4 & 26.5 & 0 & 1921 \\
\hline 1950-1959 & 66033 & 4 & 7.4 & 0 & 1933 \\
\hline 1960-1969 & 176351 & 4.7 & 2.8 & 1 & 1941 \\
\hline 1970-1979 & 415873 & 5.8 & 1.5 & 18 & 1949 \\
\hline 1980-1989 & 497654 & 7.5 & 0.6 & 61 & 1949 \\
\hline $1990+$ & 356814 & 6.7 & 0.3 & 73 & 1950 \\
\hline Total & 1535600 & 6.2 & 1.9 & 42 & 1947 \\
\hline \multicolumn{6}{|c|}{$\begin{array}{l}\text { Abbreviation: } \mathrm{mGy}=\text { milliGray. } \\
\text { a } \text { Percentage of annual dose estimates for which a badge dose reading was available. }\end{array}$} \\
\hline
\end{tabular}


Table 2. Summary information on dose, years worked, and year of birth by year first worked, US Radiologic Technologists study, 1983-2008

\begin{tabular}{|l|c|c|c|c|}
\hline $\begin{array}{l}\text { Year first } \\
\text { worked }\end{array}$ & Women & $\begin{array}{c}\text { Mean total } \\
\text { years } \\
\text { worked }\end{array}$ & $\begin{array}{c}\text { Mean total } \\
\text { cumulative } \\
\text { breast dose } \\
\text { (mGy) }\end{array}$ & $\begin{array}{c}\text { Mean } \\
\text { birth year }\end{array}$ \\
\hline Pre-1930 & 131 & 28.1 & 1168 & 1905 \\
\hline $1930-1939$ & 814 & 21.0 & 556 & 1913 \\
\hline $1940-1949$ & 3339 & 20.1 & 180 & 1923 \\
\hline $1950-1959$ & 12100 & 18.2 & 50 & 1935 \\
\hline $1960-1969$ & 25620 & 19.9 & 27 & 1945 \\
\hline $1970-1979$ & 40379 & 17.4 & 14 & 1954 \\
\hline $1980+$ & 1155 & 11.4 & 6 & 1951 \\
\hline Total & 83538 & 18.4 & 37 & 1947 \\
\hline Abbreviation: mGy milliGray. & & & \\
\hline
\end{tabular}

and year first worked based on findings from our earlier workhistory analyses. We also assessed excess absolute risks. As a secondary component of our analysis, we examined dose-response ERR for breast cancer mortality. In sensitivity analyses, we evaluated dose-response ERR for breast cancer incidence using external comparisons with US incidence rates from SEER population-based cancer registries.

Poisson regression was used to calculate ERRs and 95\% confidence intervals (CIs) for breast cancer incidence or mortality, in a person-year table stratified by age, 5-year lagged cumulative breast dose, and other factors (for more details see Supplement Data B). Rates were described using ERR models of the form $\lambda_{0}\left(a, b, z_{\mathrm{o}}\right)\left[1 \operatorname{ERR}\left(d, z_{1}\right)\right]$, in which $\lambda_{0}\left(a, b, z_{\mathrm{o}}\right)$ represents the background rates depending on age $(a)$, birth cohort $(b)$ and other factors $\left(z_{0}\right)$. The ERR depends on dose $(d)$ and, as necessary, various effect modifiers $\left(z_{1}\right)$. The primary risk model is described in detail in Supplementary Data D.

We evaluated known or suspected breast cancer risk factors to identify those which improved model fit or had an appreciable effect on inference about the radiation dose-response. Factors included in the final models were attained age, birth cohort, number of live births, menopausal status, body mass index (BMI) at baseline, family breast cancer history, alcohol consumption, and use of hormone replacement therapy. Other potential risk factors, including race, marital status, smoking, and other reproductive factors were not included in the primary analyses as their inclusion neither improved model fit nor had any appreciable effect on inference about the radiation dose-response association. With the exception of menopause age and status, missing data for risk factors were represented by missing-value indicator variables. A single imputation method was used to assign menopause age to women who were premenopausal at the time of last reported menopause status (Supplementary Data C). Standardised incidence/mortality ratio (SIR, SMR) analyses based on SEER incidence and mortality rates (Surveillance Epidemiology and End Results (SEER) Program, 2015) were used for some supplementary analyses.

Maximum-likelihood estimates were computed using AMFIT (Preston et al, 2015). Two-sided hypothesis tests and CI's were based on likelihood ratio tests (Cox and Hinckley, 1974).

\section{RESULTS}

Incidence. Among 66915 women with 1089502 years of followup and 1922 reported first primary breast cancers, incidence increased with age with a complex interaction between age and menopausal status. Supplementary Data D contains information on the fitted rate model and includes a plot illustrating how rates varied with age, birth cohort, and menopausal age. Incidence did not vary substantially by race or marital status, but was higher in those with more education, current and former smokers, greater reported alcohol consumption, higher BMI at baseline, and a family history of breast cancer (see Supplementary Table D1 for details). Risks were higher in nulliparous women, declined with increasing number of children, and were slightly increased among those using hormone replacement therapy (see Supplementary Table D2 for details). There was no association with age at menarche. Age-specific breast cancer rates have decreased markedly with increasing birth year in the USRT (Supplementary Table D1).

The magnitude of the estimated linear ERR dose-response slope depended on the nature of the birth cohort adjustment. Without birth cohort adjustment, there was a positive dose-response association $(P<0.001)$ with an estimated ERR at $100 \mathrm{mGy}$ of 0.12 (95\% CI: 0.03-0.25). In contrast, using a simple log-linear adjustment for birth cohort, the estimated ERR at $100 \mathrm{mGy}$ was 0.05 (95\% CI: -0.02 to $0.16 ; P=0.4$ ). Adjustment for birth cohort had little effect on other parameters in the risk model (Supplementary Table D1). In view of the unusual nature of the simple birth cohort trend, our primary analyses were stratified on birth cohort. We also examined the extent to which the breast cancer risk varied with time-dependent length of employment as a radiological technologist. These analyses (details not shown) provided no indication of a significant trend in risk with employment duration and the estimated magnitude of the trend was small, $\sim 1 \%$ change in risk per decade increase in employment length.

The upper portion of Table 3 and Figure 1A present results of a stratified analysis with separate ERR estimates for each of four birth cohorts (before 1930, 1930-1939, 1940-1949, and 1950+). Supplementary Table D2 contains information on the birth cohortspecific distributions of various risk factors. A linear dose-response association was observed for cohort members born before 1930 with an estimated ERR at $100 \mathrm{mGy}$ of 0.16 (95\% CI: $0.03-0.39$ ). There was no indication of a positive dose-response association in the other birth cohorts and weak evidence of heterogeneity $(P=0.08)$. When the ERR was assumed constant over strata, the estimate (ERR at $100 \mathrm{mGy}=0.07 ; 95 \% \mathrm{CI}:-0.10$ to 0.19 , $P=0.09$ ) was slightly larger than that in an unstratified model in which baseline rates were assumed to vary log-linearly with birth cohort. Table 4 presents ERR estimates within year first worked categories (before 1950, 1950-1959, 1960-1969, and 1970+). There was a dose-response association in the earliest category (ERR at $100 \mathrm{mGy}=0.11$ ) with no indication of increased risks for the other three groups, but only weak evidence of heterogeneity over first year worked categories $(P=0.10)$. Estimated excess absolute rates exhibited similar variation by birth cohort (results not shown).

The SEER-based SIR estimate was 1.08 (95\% CI: 1.04-1.14). Birth cohort-specific ERR estimates in an SIR model were similar to those from parametric models (details not shown).

Mortality. The mortality analyses were based on 83538 women in the USRT Cohort with 1722303 years of mortality follow-up who completed at least one study questionnaire. There were 586 breast cancer deaths, of which 119 were in women who self-reported breast cancer and were included in the cohort of 66915 women in the incidence analyses who completed at least two study questionnaires and 349 among women who reported a breast cancer diagnosis before the date of completion of the first survey. Only 20\% (118) of the breast cancer deaths occurred among women who had never reported breast cancer. While breast cancer 
Table 3. ERR estimates for breast cancer incidence and mortality by birth cohort, US Radiologic Technologists study, 1983-2008

\begin{tabular}{|c|c|c|c|c|c|c|}
\hline Year of birth & ERR at $100 \mathrm{mGy}^{\mathrm{a}}$ & $95 \% \mathrm{Cl}$ & $P$-value & $\begin{array}{l}\text { Fitted excess } \\
\text { cases }\end{array}$ & $\begin{array}{l}\text { Observed } \\
\text { cases }\end{array}$ & $\begin{array}{c}\text { Mean } \\
\text { dose (mGy) }\end{array}$ \\
\hline \multicolumn{7}{|l|}{ Incidence } \\
\hline Before 1930 & 0.16 & $0.03,0.39$ & 0.01 & 44.2 & 216 & 167 \\
\hline 1940-1949 & -0.14 & $<-0.5,0.22$ & 0.4 & -25.8 & 745 & 25 \\
\hline \multirow[t]{2}{*}{$1950+$} & -0.25 & $<-0.5,0.31$ & 0.27 & -27.9 & 555 & 14 \\
\hline & & \multicolumn{2}{|c|}{$P_{\text {het }}=0.08$} & & & \\
\hline \multicolumn{7}{|l|}{ Mortality } \\
\hline Before 1930 & 0.26 & $0.08,0.63$ & $<0.001$ & 43.7 & 128 & 217 \\
\hline 1930-1939 & 0.28 & $-0.08,0.89$ & 0.26 & 19.5 & 159 & 51 \\
\hline 1940-1949 & 1.61 & $0.20,4.50$ & 0.01 & 52.6 & 190 & 25 \\
\hline \multirow[t]{2}{*}{$1950+$} & 0.61 & $<-0.5,4.70$ & $>0.5$ & 8.6 & 109 & 14 \\
\hline & & \multicolumn{2}{|c|}{$P_{\text {het }}=0.35$} & & & \\
\hline
\end{tabular}

was the most common cause of death among the 1922 breast cancer cases in the incidence analyses, most of the women in this group $(87 \%)$ were still alive at the end of the mortality follow-up.

The associations between non-radiation lifestyle and reproductive factors and breast cancer mortality were generally similar to those seen for incidence. Age-specific breast cancer mortality rates for cohort members decreased over time (see Supplement Data E for details).

Without birth cohort adjustment, there was a positive doseresponse association $(P<0.001)$ with an ERR at $100 \mathrm{mGy}$ of 0.71 (95\% CI: $0.31-1.43)$ and no evidence of non-linearity $(P>0.5)$. As shown in the lower portion of Table 3 , in a stratified analysis in which the ERR was assumed to be the same in all birth cohorts, the estimated ERR at $100 \mathrm{mGy}$ was $0.31(P<0.001)$. Although there was no evidence of significant heterogeneity in the ERRs over birth cohort $(P=0.35)$, as with incidence, the experience of the early workers is the primary determinant of the risk (see Table 3 and Figure 1B). As with incidence, when birth cohort associations were described using a log-linear birth cohort trend, evidence for a radiation association was greatly reduced: the estimated ERR at 100 mGy was essentially zero (95\% CI: $<-0.03$ to $0.10 ; P>0.5$ ). An SMR analysis indicated that mortality was slightly lower than expected (SMR $=0.9 ; 95 \%$ CI 0.82-0.97) with birth cohort-specific ERR estimates similar to those based on internal comparisons (details not shown).

\section{DISCUSSION}

Analyses of breast cancer incidence and mortality rates in the USRT Cohort stratified on birth cohort suggest that low-tomoderate-dose protracted occupational radiation exposure is associated with increased breast cancer risk. Statistically significant trends were seen for incidence and mortality among women born before 1930. The findings, especially for incidence, are less clear for more recent birth cohorts where lifetime cumulative doses are much lower.

There were no indications of a dose-response association for either incidence or mortality when the variation in age-specific rates with birth cohort was modelled using continuous log-linear or log-quadratic functions of birth year. However, using such simple parametric birth cohort trend models may underestimate the radiation dose-response association because of intrinsic confounding between estimated cumulative breast dose and birth year $(r=-0.58)$ and the marked variation in age-specific rates with birth cohort. The effect of this confounding is exacerbated by the large uncertainties in individual dose estimates for the early (higher dose) years when badge dose readings were unavailable. Concern about intrinsic confounding is supported by the contrast between the decline in age-specific incidence rates with birth cohort in the USRT study and the increase with some leveling off in recent years seen in US cancer registry data (Devesa et al, 1995; Edwards et al, 2014) and in age period cohort analyses of Danish (Anderson et al, 2013) and Norwegian (Weedon-Fekjaer et al, 2012) population data.

Age-specific breast cancer mortality rates have declined over time in the USRT Cohort, a pattern broadly similar to that seen in age-standardised US breast cancer mortality rates (Tarone et al, 1997; Jatoi et al, 2005). However, the marked effect of adjusting for birth cohort using smooth models on the radiation dose-response further suggests confounding between dose and birth cohort.

Despite this confounding, both the incidence and mortality data indicated that radiation is associated with increased breast cancer risks in the earliest workers with little evidence of increased risk in more recent workers who received lower doses. The findings from the mortality analyses are consistent with results of the workhistory-based analyses that showed increased breast cancer mortality for those who started working before 1950. As there was some indication of heterogeneity in the radiation ERRs with year first worked or birth cohort, the birth cohort-stratified analyses with a single ERR trend estimate appear to provide the most useful characterisation of the breast cancer dose-response association.

The USRT has a number of strengths. It is a large nationwide cohort with individualised dose estimates, long-term follow-up, detailed information on potential confounders, and a high confirmation rate for the self-reported incident cases. The individualised bone marrow dose estimates were used in a doseresponse analysis of chromosome translocation frequency (Little et al, 2014) that found radiation dose-response trends similar to those seen in other populations.

This study has a number of limitations. For technologists who began working in more recent decades, power to detect associations was limited owing to low cumulative occupational radiation doses. Incidences may have been under-reported during follow-up as this information was captured in follow-up surveys administered every 8 to 10 years. Underascertainment of breast cancers should not have led to biased risk estimates unless cohort members with higher doses were more likely to report a case or if dose was more 
A

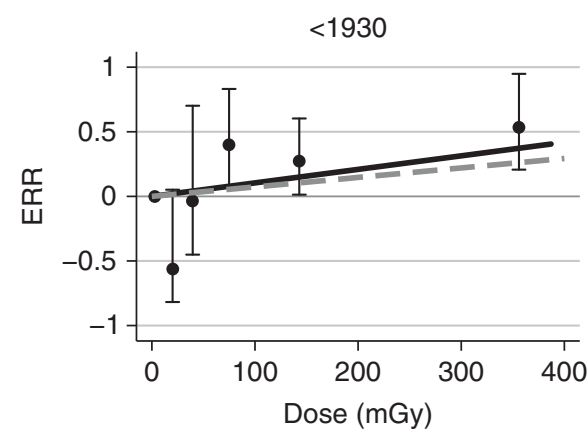

1940-49

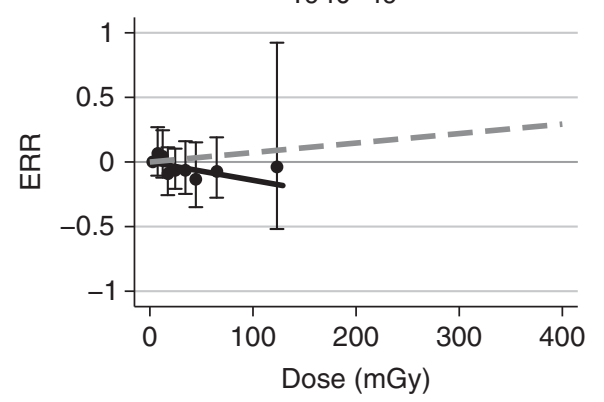

B

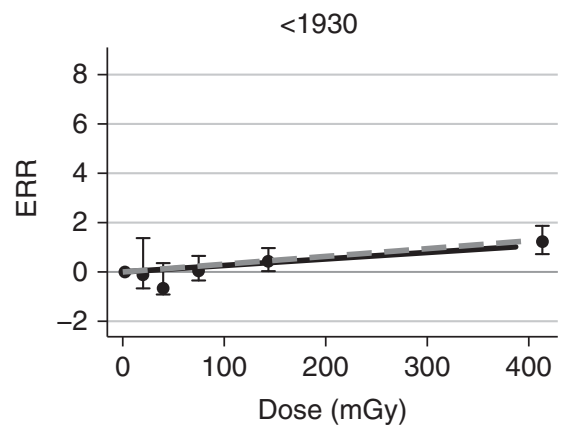

1940-49

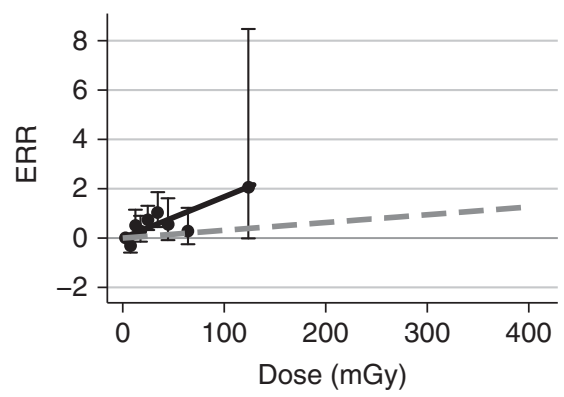

Incidence
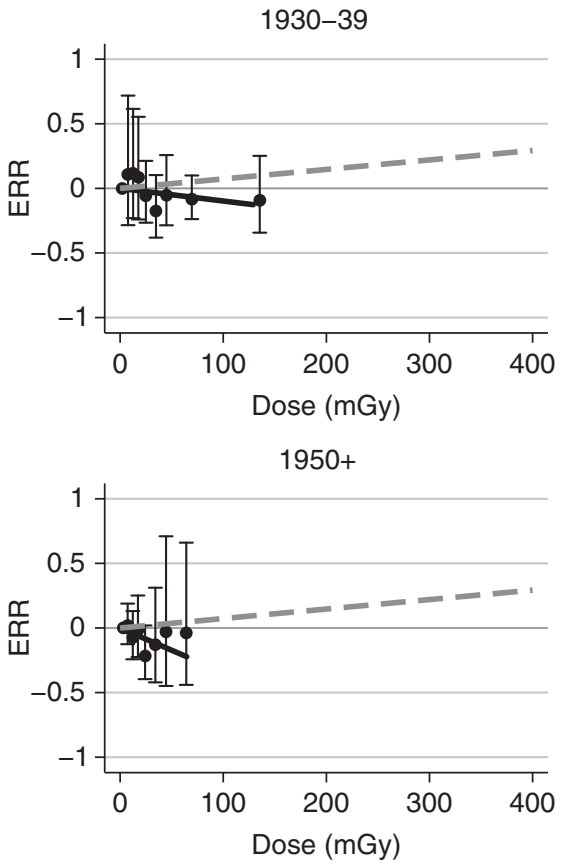

Mortality

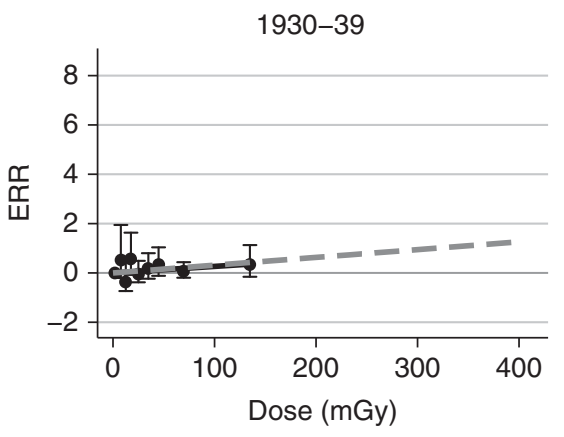

$1950+$

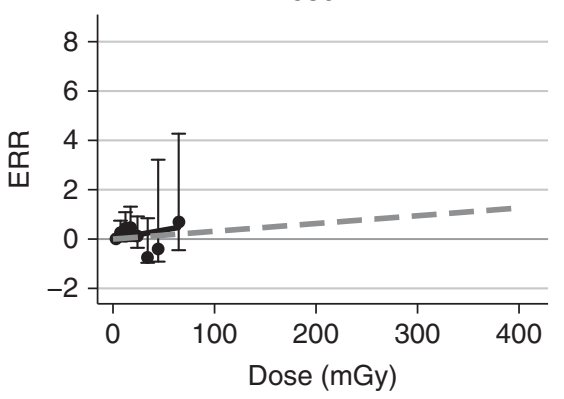

Figure 1. Birth cohort-specific fitted breast cancer incidence (A) and mortality (B) dose-response curves (solid lines) with categorical excess relative risk estimates (ERRs) (closed circles) and 95\% confidence limits. The dashed lines are the fitted linear dose-response curves assuming that the ERR is the same in all birth cohorts.

strongly associated with aggressive and rapidly fatal breast tumour types that were less likely to have been captured via self-report. However, Freedman et al (2006) found that only $\sim 3 \%$ of breast cancers were not reported by survey respondents, suggesting that underascertainment is unlikely to be an important source of bias. As dose estimates and risk factor data were available only for technologists who survived to at least the mid-1980s or, for the incidence analyses, the mid-1990s, older and higher dose technologists are under-represented in these analyses. While this reduces the power of the study, it seems unlikely that it would bias the risk estimates for the study period.
Despite the carefully designed dosimetry system, uncertainties, and, more importantly, the potential for systematic errors in the dose estimates before 1960, and for most cohort members, the mid-1970s, for the early years when badge dose measurements were lacking and information on dose distributions is scarce are the most important limitations of this analysis. Only $\sim 30 \%$ of individual worker total doses were based on actual badge readings. The correlation between birth cohort and total cumulative dose, together with the uncertainty in the dose estimates (particularly for the early years), make it difficult to disentangle birth cohort and dose-response associations. Lifestyle differences between early 
Table 4. ERRs and $95 \%$ Cls for breast cancer incidence by year first worked, US Radiologic Technologists study, 1983-2008

\begin{tabular}{|c|c|c|c|c|c|c|}
\hline Year first worked & $\begin{array}{c}\text { ERR at } \\
100 \mathrm{mGy}^{\mathrm{a}}\end{array}$ & $95 \% \mathrm{Cl}$ & $P$-value & $\begin{array}{l}\text { Fitted excess } \\
\text { cases }\end{array}$ & $\begin{array}{l}\text { Observed } \\
\text { cases }\end{array}$ & $\begin{array}{c}\text { Mean } \\
\text { dose (mGy) }\end{array}$ \\
\hline Before 1950 & 0.11 & $0.03,0.39$ & 0.03 & 31 & 163 & 213 \\
\hline 1950-1959 & -0.04 & $<-0.3,0.11$ & $>0.5$ & -8.6 & 450 & 49 \\
\hline 1960-1969 & -0.19 & $<-0.5,0.22$ & 0.18 & -25.8 & 684 & 26 \\
\hline \multirow[t]{2}{*}{$1970+$} & -0.33 & $<-0.5,0.33$ & 0.22 & -27.9 & 625 & 14 \\
\hline & & \multicolumn{2}{|c|}{ Phet $=0.10$} & & & \\
\hline
\end{tabular}

Table 5. ERR estimates for breast cancer incidence and mortality in the USRT study (1983-2008) and previous studies

\begin{tabular}{|c|c|c|c|c|c|c|}
\hline & \multicolumn{3}{|c|}{ Incidence } & \multicolumn{3}{|c|}{ Mortality } \\
\hline Atomic bomb survivors ${ }^{a}$ & 1073 & $0.19^{b}$ & $0.12,0.28$ & 324 & 0.16 & $0.09,0.24$ \\
\hline Pooled analysis $^{c}$ & 245 & 0.07 & $0.04,0.12$ & & & \\
\hline Techa River Cohort $^{d}$ & 109 & 0.19 & $-0.06,0.61$ & & & \\
\hline \multicolumn{7}{|c|}{ 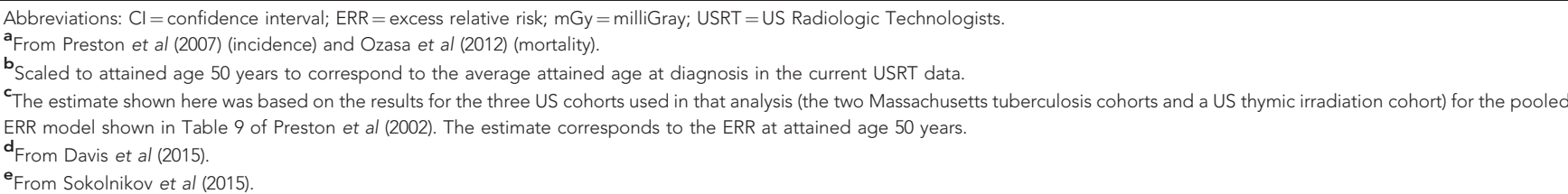 } \\
\hline
\end{tabular}

workers and the general population may account for some of the unusual birth cohort trends, but the persistence of these differences after adjustment and the similarity of the risk factor associations to those observed in other studies (Colditz et al, 2006), suggests that lifestyle differences are unlikely to account for the patterns observed. Table 5 contrasts the breast cancer incidence and mortality ERR estimates for the USRT population with those from several other cohort studies. Although the USRT mortality risk estimate is roughly two times that in atomic bomb survivor studies (Preston et al, 2007; Ozasa et al, 2012), the incidence ERR for the current analysis is similar to the risks for cohorts in the pooled analysis of atomic bomb survivors and patients exposed to radiation from medical sources (Preston et al, 2002). The difference in the ERRs for Japanese and western women appeared to be largely due to marked differences in the baseline rates in Japan from those in western countries. The latest incidence ERR estimate in the cohort of Russian women who received chronic low-dose-rate environmental exposures (Davis et al, 2015) is only slightly higher than that seen in this study, whereas the breast cancer mortality ERR in the Mayak plutonium production workers (Sokolnikov et al, 2015) was somewhat lower than our USRT estimate.

The USRT is the first large cohort of medical radiation workers with dose estimates based on a comprehensive, individualised dose reconstruction, extended follow-up, large numbers of female technologists and breast cancer cases, and extensive information on breast cancer risk factors and potential confounders. Despite the difficulty of disentangling variations in breast cancer rates with dose and birth cohort and the shortcomings of the early-worker dose estimates, a radiation dose-response association was observed for both incidence and mortality in those born before 1930 .
Occupational radiation dose to the breast was positively associated with breast cancer risk. The risk was more pronounced for women born before 1930 who began working before 1950 when mean annual doses ( $37 \mathrm{mGy}$ ) were considerably higher than in later years $(1.3 \mathrm{mGy})$. However, because of the uncertainties and possible systematic errors in the occupational dose estimates before 1960 these findings should be treated with caution.

\section{ACKNOWLEDGEMENTS}

JS Miller, DL Preston, and MM Doody had primary responsibility for data preparation. DL Preston organised the data, carried out the primary analyses, and drafted the paper. SL Simon, JS Miller, and DL Preston worked on the development of the dosimetry system. All authors participated in preparing the final version of the paper. The authors are grateful for the detailed and helpful comments of the three referees.

We thank the radiologic technologists who participated in the study, Jerry Reid of the American Registry of Radiologic Technologists for continued support, and Diane Kampa and Allison Iwan of the University of Minnesota for data management and collection. We are also grateful to Drs. Amy Berrington de Gonzalez and Robert Hoover for helpful suggestions. This research was funded by the intramural program of the Division of Cancer Epidemiology and Genetics, National Cancer Institute, National Institutes of Health, Department of Health and Human Services.

This work was supported by the Intramural Research Program of the National Institutes of Health and the National Cancer Institute 


\section{CONFLICT OF INTEREST}

The authors declare no conflict of interest.

\section{REFERENCES}

Anderson WF, Rosenberg PS, Petito L, Katki HA, Ejlertsen B, Ewertz M, Rasmussen BB, Jensen MB, Kroman N (2013) Divergent estrogen receptor-positive and -negative breast cancer trends and etiologic heterogeneity in Denmark. Int J Cancer 133(9): 2201-2206.

Bernstein JL, Thomas DC, Shore RE, Robson M, Boice Jr JD, Stovall M, Andersson M, Bernstein L, Malone KE, Reiner AS, Lynch CF, Capanu M, Smith SA, Tellhed L, Teraoka SN, Begg CB, Olsen JH, Mellemkjaer L, Liang X, Diep AT, Borg A, Concannon P, Haile RW. Group WSC (2013) Contralateral breast cancer after radiotherapy among BRCA1 and BRCA2 mutation carriers: a WECARE study report. Eur J Cancer 49(14): 2979-2985.

Boice Jr JD, Mandel JS, Doody MM, Yoder RC, McGowan R (1992) A health survey of radiologic technologists. Cancer 69(2): 586-598.

Colditz GA, Baer HJ, Tamimi RM (2006) Breast cancer. In Cancer Epidemiology and Prevention, Schottenfeld Jr D, Fraumeni FJ (eds) 2nd edn, Chapter 51, pp 995-1012. Oxford University Press: Oxford, UK.

Cox DR, Hinckley DV (1974) Theoretical Statistics. Chapman \& Hall: New York, NY, USA.

Davis F, Krestinina LY, Preston D, Epifanova S, Degteva M, Akleyev A (2015) Solid cancer incidence in the Techa River Incidence Cohort: 1956-2007. Radiat Res 184(1): 56-65.

Devesa SS, Blot WJ, Stone BJ, Miller BA, Tarone RE, Fraumeni JF Jr (1995) Recent cancer trends in the United States. J Natl Cancer Inst 87(3): $175-182$.

Doody MM, Freedman DM, Alexander BH, Hauptmann M, Miller JS, Rao RS, Mabuchi K, Ron E, Sigurdson AJ, Linet MS (2006) Breast cancer incidence in U.S. radiologic technologists. Cancer 106(12): 2707-2715.

Edwards BK, Noone AM, Mariotto AB, Simard EP, Boscoe FP, Henley SJ, Jemal A, Cho H, Anderson RN, Kohler BA, Eheman CR, Ward EM (2014) Annual Report to the Nation on the status of cancer, 1975-2010, featuring prevalence of comorbidity and impact on survival among persons with lung, colorectal, breast, or prostate cancer. Cancer 120(9): 1290-1314.

Eidemuller M, Ostroumova E, Krestinina L, Akleyev A, Jacob P (2008) Analysis of solid cancer mortality in the Techa River cohort using the two-step clonal expansion model. Radiat Res 169(2): 138-148.

Freedman DM, Sigurdson AJ, Doody MM, Love-Schnur S, Linet MS (2006) Comparison between cancers identified by state cancer registry, selfreport, and death certificate in a prospective cohort study of US Radiologic Technologists. Int J Epidemiol 35(2): 495-497.

Howe GR, McLaughlin J (1996) Breast cancer mortality between 1950 and 1987 after exposure to fractionated moderate-dose-rate ionizing radiation in the Canadian fluoroscopy cohort study and a comparison with breast cancer mortality in the atomic bomb survivors study. Radiat Res 145(6): 694-707.

Jatoi I, Anderson WF, Rao SR, Devesa SS (2005) Breast cancer trends among black and white women in the United States. J Clin Oncol 23(31): 7836-7841.

Langholz B, Thomas DC, Stovall M, Smith SA, Boice Jr JD, Shore RE, Bernstein L, Lynch CF, Zhang X, Bernstein JL (2009) Statistical methods for analysis of radiation effects with tumour and dose location-specific information with application to the WECARE study of asynchronous contralateral breast cancer. Biometrics 65(2): 599-608.

Linet MS, Kim KP, Miller DL, Kleinerman RA, Simon SL, Berrington de Gonzalez A (2010) Historical review of occupational exposures and cancer risks in medical radiation workers. Radiat Res 174(6): 793-808.

Little MP, Boice JD Jr (1999) Comparison of breast cancer incidence in the Massachusetts tuberculosis fluoroscopy cohort and in the Japanese atomic bomb survivors. Radiat Res 151(2): 218-224.

Little MP, Kwon D, Doi K, Simon SL, Preston DL, Doody MM, Lee T, Miller JS, Kampa DM, Bhatti P, Tucker JD, Linet MS, Sigurdson AJ (2014) Association of chromosome translocation rate with low dose occupational radiation exposures in U.S. Radiologic Technologists. Radiat Res 182(1): $1-17$.

Madigan MP, Ziegler RG, Benichou J, Byrne C, Hoover RN (1995) Proportion of breast cancer cases in the United States explained by well-established risk factors. J Natl Cancer Inst 87(22): 1681-1685.

Mohan AK, Hauptmann M, Linet MS, Ron E, Lubin JH, Freedman DM, Alexander BH, Boice Jr. JD, Doody MM, Matanoski GM (2002) Breast cancer mortality among female radiologic technologists in the United States. J Natl Cancer Inst 94(12): 943-948.

Muirhead C, O’Hagan J, Haylock R, Phillipson M, Willcock T, Berridge G, Zhang W (2009) Mortality and cancer incidence following occupational radiation exposure: third analysis of the National Registry for Radiation Workers. Br J Cancer 100(1): 206-212.

Ostroumova E, Preston D, Ron E, Krestinina L, Davis F, Kossenko M, Akleyev A (2008) Breast cancer incidence following low-dose rate environmental exposure: Techa River Cohort, 1956-2004. Br J Cancer 99(11): 1940-1945.

Ozasa K, Shimizu Y, Suyama A, Kasagi F, Soda M, Grant EJ, Sakata R, Sugiyama H, Kodama K (2012) Studies of the mortality of atomic bomb survivors, Report 14, 1950-2003: an overview of cancer and noncancer diseases. Radiat Res 177(3): 229-243.

Preston DL, Lubin JH, Pierce DA, McConney ME, Shilnikova NS (2015) Epicure Risk Regression and Person-Year Computation Software: Command Summary and User Guide. Risk Sciences International: Ottawa, ON, Canada.

Preston DL, Mattsson A, Holmberg E, Shore R, Hildreth NG, Boice Jr JD (2002) Radiation effects on breast cancer risk: a pooled analysis of eight cohorts. Radiat Res 158(2): 220-235.

Preston DL, Ron E, Tokuoka S, Funamoto S, Nishi N, Soda M, Mabuchi K, Kodama K (2007) Solid cancer incidence in atomic bomb survivors: 1958-1998. Radiat Res 168(1): 1-64.

Radiation Epidemiology Branch (2015) United States Radiologic Technologists (USRT) Study: Homepage. National Cancer Institute: Bethesda, MD USA.

Ronckers CM, Doody MM, Lonstein JE, Stovall M, Land CE (2008) Multiple diagnostic X-rays for spine deformities and risk of breast cancer. Cancer Epidemiol Biomarkers Prev 17(3): 605-613.

Sigurdson AJ, Doody MM, Rao RS, Freedman DM, Alexander BH, Hauptmann M, Mohan AK, Yoshinaga S, Hill DA, Tarone R, Mabuchi K, Ron E, Linet MS (2003) Cancer incidence in the US radiologic technologists health study, 1983-1998. Cancer 97(12): 3080-3089.

Simon SL, Preston DL, Linet MS, Miller JS, Sigurdson AJ, Alexander BH, Kwon D, Yoder RC, Bhatti P, Little MP, Rajaraman P, Melo D, Drozdovitch V, Weinstock RM, Doody MM (2014) Radiation organ doses received in a nationwide cohort of U.S. Radiologic technologists: methods and findings. Radiat Res 182(5): 507-528.

Simon SL, Weinstock RM, Doody MM, Neton J, Wenzl T, Stewart P, Mohan AK, Yoder RC, Hauptmann M, Freedman DM, Cardarelli J, Feng HA, Bouville A, Linet M (2006) Estimating historical radiation doses to a cohort of U.S. radiologic technologists. Radiat Res 166(1, Part 2): 174-192.

Sokolnikov M, Preston D, Gilbert E, Schonfeld S, Koshurnikova N (2015) Radiation effects on mortality from solid cancers other than lung, liver, and bone cancer in the Mayak Worker Cohort: 1948-2008. PLoS One 10(2): e0117784.

Sprague BL, Trentham-Dietz A, Egan KM, Titus-Ernstoff L, Hampton JM, Newcomb PA (2008) Proportion of invasive breast cancer attributable to risk factors modifiable after menopause. Am J Epidemiol 168(4): 404-411.

Surveillance Epidemiology and End Results (SEER) Program (2015) SEER ${ }^{*}$ Stat Database: Mortality - All COD, Aggregated With State, Total U.S. (1969-2012) < Katrina/Rita Population Adjustment >, National Cancer Institute, DCCPS, Surveillance Research Program, Surveillance Systems Branch, released April 2015Underlying mortality data provided by NCHS. Available at: www.cdc.gov/nchs.

Tarone RE, Chu KC, Gaudette LA (1997) Birth cohort and calendar period trends in breast cancer mortality in the United States and Canada. J Natl Cancer Inst 89(3): 251-256.

United Nations Scientific Committee on the Effects of Atomic Radiation (2008) Effects of Ionizing Radiation - UNSCEAR 2006 Report to the General Assmbly with Scientific Annexes A and B. 6th edn, Vol. I, United Nations Sales No. E.08.IX. United Nations: New York, NY, USA. 
Weedon-Fekjaer H, Bakken K, Vatten LJ, Tretli S (2012) Understanding recent trends in incidence of invasive breast cancer in Norway: age-periodcohort analysis based on registry data on mammography screening and hormone treatment use. BMJ 344: e299.

Zeeb H, Blettner M, Langner I, Hammer GP, Ballard TJ, Santaquilani M, Gundestrup M, Storm H, Haldorsen T, Tveten U, Hammar N, Linnersjo A, Velonakis E, Tzonou A, Auvinen A, Pukkala E, Rafnsson V, Hrafnkelsson J (2003) Mortality from cancer and other causes among airline cabin attendants in Europe: a collaborative cohort study in eight countries. Am J Epidemiol 158(1): 35-46.

This work is published under the standard license to publish agreement. After 12 months the work will become freely available and the license terms will switch to a Creative Commons AttributionNonCommercial-Share Alike 4.0 Unported License.

Supplementary Information accompanies this paper on British Journal of Cancer website (http://www.nature.com/bjc) 